\title{
Differential expression of serum microRNAs in cirrhosis that evolve into hepatocellular carcinoma related to hepatitis B virus
}

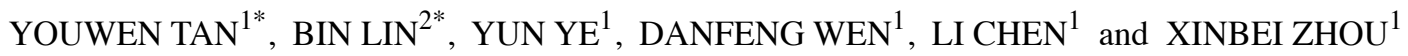 \\ ${ }^{1}$ Department of Hepatosis, The Third Hospital of Zhenjiang Affiliated to Jiangsu University, Zhenjiang, Jiangsu; \\ ${ }^{2}$ Department of Infectious Diseases, Jintan Hospital Affiliated to Jiangsu University, Changzhou, Jiangsu, P.R. China
}

Received December 6, 2014; Accepted March 24, 2015

DOI: $10.3892 /$ or.2015.3924

\begin{abstract}
Circulating microRNAs (miRNAs) exist stably in body fluids and are potential biomarkers for hepatocellular carcinoma (HCC). Twenty-five patients with cirrhosis that evolved into HCC, who were treated at The Third Hospital of Zhenjiang Affiliated to Jiangsu University between January 2005 and December 2012, were enrolled. In the discovery stage, 2 serum samples pooled from 3 cirrhosis and $3 \mathrm{HCC}$ samples were subjected to deep sequencing. Subsequently, differential expression of miRNAs was validated by quantitative reverse transcription-polymerase chain reaction (qRT-PCR) in the serum samples from an independent cohort of 22 patients with cirrhosis and HCC. Twenty-two miRNAs showed a $>2$-fold upregulation $(\mathrm{P}<0.01)$, and 2 miRNAs showed a $>2$-fold downregulation $(\mathrm{P}<0.01)$ in the cirrhosis and HCC samples. Using the comparative $\mathrm{Ct}$ method, we calculated the $2^{-\Delta \Delta \mathrm{Ct}}$ for 40 candidate miRNAs in the sample sets. Eight of the 40 miRNAs demonstrated significantly differential expression levels between the disease categories. The miRNAs exhibiting differential expression were hsa-miR-122-5p, hsa-miR-199a-5p, hsa-miR-486-5p, hsa-miR-193b-5p, hsa-miR-206, hsamiR-141-3p, hsa-miR-192-5p and hsa-miR-26a-5p. We identified the miRNAs differentially expressed in cirrhosis that evolved into hepatitis B virus-related HCC.
\end{abstract}

\section{Introduction}

Hepatocellular carcinoma (HCC) is a leading cause of cancer-related mortality worldwide, and is associated with persistent infection from hepatitis $\mathrm{B}$ virus (HBV) or hepatitis $\mathrm{C}$ virus (HCV). These viruses play key roles in hepatocarcinogenesis; and therefore, $\mathrm{HCC}$ is highly prevalent in China due to chronic $\mathrm{HBV}$ and $\mathrm{HCV}$ infection (1). HCC patients show

Correspondence to: Youwen Tan, Department of Hepatosis, The Third Hospital of Zhenjiang Affiliated to Jiangsu University, Zhenjiang, Jiangsu, P.R. China

E-mail: tyw915@sina.com

*Contributed equally

Key words: microRNA, hepatocellular carcinoma, hepatitis B virus, cirrhosis the shortest survival time among cancer patients, with most patients dying within 12 months of HCC tumor development (2). Furthermore, only $30-40 \%$ of HCC patients are found eligible for potentially curative intervention (3) upon diagnosis, partially due to the lack of highly sensitive and specific early-detection measures. Therefore, the effective identification of new markers for HCC is urgently needed.

MicroRNAs (miRNAs) are a class of single-stranded noncoding small RNAs (19-24 nt) that regulate the gene expression network and are known to contribute to a diverse range of functions, including development, apoptosis, differentiation and oncogenesis by binding to specific target mRNAs (4). Circulating miRNAs exist stably in body fluids and were first reported as a newly identified family of miRNAs by Valadi et al in 2007 (5). It has become clear that miRNAs potentially regulate all aspects of cellular activity. Recent studies have provided clear evidence that miRNAs are abundant in the liver and modulate a diverse spectrum of liver functions, including differentiation and development, metabolism, apoptotic cell death, cell proliferation, viral infection and tumorigenesis $(6,7)$. Deregulation of miRNA expression may be a key pathogenic mechanism in many liver diseases, such as HCC, viral hepatitis and polycystic liver disease (8-11).

Differential miRNA expression in HCC and non-tumor tissue has been reported in numerous studies (12-17). Several differentially expressed serum miRNAs, including miR-16, miR-122, miR-21, miR-223, miR-24, miR-27a, miR-375 and let-7f have been recently reported in patients with HCC, when compared with hepatitis B patients and healthy individuals $(18,19)$. However, the differentially expressed miRNAs found in these studies varied only between different individuals, and these differences were either investigated in control vs. HCC patients or cirrhosis vs. HCC patients. In the present study, we investigated miRNA expression profiles in cirrhosis patients who went on to develop hepatitis B virus-related HCC.

\section{Materials and methods}

Ethics statement. The present study was approved by the Medical Ethics Committee of The Third Hospital of Zhenjiang Affiliated to Jiangsu University, Zhenjiang, China, and was conducted in accordance with the Declaration of Helsinki. Written informed consent was obtained from each patient prior to their participation in the present study. 
Table I. Demographics and clinical features of the patients.

\begin{tabular}{|c|c|c|c|c|c|c|c|c|}
\hline No. & Gender & $\begin{array}{c}\text { Age } \\
\text { (years) }\end{array}$ & $\begin{array}{c}\text { Smoking } \\
\text { status }\end{array}$ & $\begin{array}{c}\text { Alcohol } \\
\text { consumption }\end{array}$ & $\begin{array}{l}\text { Antiviral } \\
\text { treatment }\end{array}$ & $\mathrm{HBeAg}$ & HBV DNA & Genotype \\
\hline 1 & $\mathrm{M}$ & 43 & Yes & No & ETV & $\mathrm{N}$ & ND & B \\
\hline 2 & M & 35 & No & Yes & LAM & $\mathrm{N}$ & ND & $\mathrm{C}$ \\
\hline 3 & M & 46 & No & No & ETV & $\mathrm{N}$ & ND & $\mathrm{C}$ \\
\hline 4 & $\mathrm{~F}$ & 44 & Yes & No & ETV & $\mathrm{P}$ & ND & $\mathrm{C}$ \\
\hline 5 & M & 53 & No & Yes & ETV & $\mathrm{N}$ & ND & B \\
\hline 6 & M & 57 & Yes & No & ETV & $\mathrm{N}$ & ND & $\mathrm{C}$ \\
\hline 7 & M & 63 & Yes & No & LAM & $\mathrm{P}$ & ND & $\mathrm{C}$ \\
\hline 8 & M & 37 & Yes & No & ETV & $\mathrm{P}$ & ND & $\mathrm{C}$ \\
\hline 9 & M & 47 & No & Yes & ETV & $\mathrm{N}$ & ND & $\mathrm{C}$ \\
\hline 10 & M & 53 & No & No & ETV & $\mathrm{N}$ & ND & $\mathrm{C}$ \\
\hline 11 & $\mathrm{~F}$ & 67 & Yes & No & LAM & $\mathrm{N}$ & ND & B \\
\hline 12 & M & 64 & Yes & No & ETV & $\mathrm{N}$ & ND & $\mathrm{C}$ \\
\hline 13 & M & 57 & No & No & ETV & $\mathrm{N}$ & ND & $\mathrm{C}$ \\
\hline 14 & M & 54 & No & No & ETV & $\mathrm{P}$ & ND & B \\
\hline 15 & M & 56 & No & No & $\mathrm{LAM}+\mathrm{ADV}$ & $\mathrm{N}$ & ND & B \\
\hline 16 & M & 57 & No & No & ETV & $\mathrm{N}$ & ND & $\mathrm{C}$ \\
\hline 17 & M & 54 & No & Yes & ETV & $\mathrm{N}$ & ND & $\mathrm{C}$ \\
\hline 18 & M & 47 & Yes & No & ETV & $\mathrm{N}$ & ND & $\mathrm{C}$ \\
\hline 19 & M & 45 & Yes & No & ETV & $\mathrm{N}$ & ND & B \\
\hline 20 & M & 44 & No & No & LAM & $\mathrm{P}$ & ND & $\mathrm{C}$ \\
\hline 21 & M & 47 & Yes & No & ETV & $\mathrm{N}$ & ND & $\mathrm{C}$ \\
\hline 22 & M & 37 & No & No & ETV & $\mathrm{N}$ & ND & B \\
\hline 23 & F & 43 & No & No & ETV & $\mathrm{P}$ & ND & B \\
\hline 24 & M & 48 & Yes & No & ETV & $\mathrm{N}$ & ND & $\mathrm{C}$ \\
\hline 25 & $\mathrm{M}$ & 51 & No & No & ETV & $\mathrm{N}$ & ND & $\mathrm{C}$ \\
\hline
\end{tabular}

M, male; F, female. LAM, lamivudine; ETV, entecavirus; ADV, adefovirus. N, negative; P, positive. ND, not determined.

Study design. A total of 25 patients with cirrhosis that evolved into HCC, who were treated at The Third Hospital of Zhenjiang Affiliated to Jiangsu University between January 2005 and December 2012, were enrolled in the present study. In the discovery stage, 2 serum pooled samples from 3 cirrhosis and 3 HCC status samples from the patients were subjected to deep sequencing using the Illumina HiSeq 2000 system (Illumina, Inc., San Diego, CA, USA) to identify statistically significant differential miRNA expression. Subsequently, differentially expressed miRNAs were validated by qRT-PCR in serum samples of an independent cohort that included 22 cirrhosis and HCC status samples from patients. All patients were positive for HBsAg, the surface antigen of HBV, for a period of at least 6 months and were not co-infected with other types of hepatitis viruses such as hepatitis A, C, D or E. Patients with any other liver disease, such as alcoholic, autoimmune or metabolic liver diseases were excluded. The diagnosis of HCC and cirrhosis was histopathologically confirmed. As this was a retrospective study, collection of clinical data from the medical records, pathology reports, and regular follow-up interviews with the subjects was utilized. Serum samples used in biochemical tests and then miRNA detection were from the same specimens.
Demographics and clinical features of the patients are listed in Table I. Biochemical characteristics of the patients with cirrhosis that evolved into HCC are listed in Table II.

Illumina sequencing and data analysis. Procedures and methods of sample collection, RNA isolation and Illumina sequencing were described in detail in our previous studies $(20,21)$.

qRT-PCR validation study and data analysis. qRT-PCRbased relative quantification of miRNAs (300 $\mu \mathrm{l}$ of serum from each participant) was performed with $\mathrm{SYBR}^{\circledR}$ Premix Ex Taq (Takara, Kyoto, Japan) according to the manufacturer's instructions using a Rotor-Gene 3000 Real-Time PCR instrument (Corbett Life Science, Sydney, Australia). miR-24 has been reported to be consistently present in human serum $(22,23)$. Moreover, our previous experience was that miR-24 maintained stable expression levels, therefore the level of miR-24 served as an internal control in the serum miRNA relative quantitative analysis (20). The specificity of each PCR product was validated by melt curve analysis at completion of the PCR amplification cycles. All samples were analyzed in triplicate, and the cycle threshold $(\mathrm{Ct})$ value was defined as the number of cycles required for the fluorescent signal to reach 
Table II. Biochemical characteristics of the patients with cirrhosis that evolved into HCC.

\begin{tabular}{|c|c|c|c|c|c|c|}
\hline \multirow[b]{2}{*}{ Variables } & \multicolumn{3}{|c|}{ Screening set } & \multicolumn{3}{|c|}{ Validation set } \\
\hline & $\begin{array}{l}\text { Cirrhosis status } \\
\qquad(n=3)\end{array}$ & $\begin{array}{l}\text { HCC status } \\
\qquad(n=3)\end{array}$ & P-value ${ }^{a}$ & $\begin{array}{l}\text { Cirrhosis status } \\
\qquad(n=22)\end{array}$ & $\begin{array}{l}\text { HCC status } \\
\quad(n=22)\end{array}$ & P-value ${ }^{a}$ \\
\hline TBIL & $13.67 \pm 6.87$ & $13.90 \pm 6.79$ & 0.701 & $16.61 \pm 9.48$ & $18.62 \pm 11.90$ & 0.573 \\
\hline ALB & $40.17 \pm 3.01$ & $41.63 \pm 3.78$ & 0.745 & $41.66 \pm 2.17$ & $41.96 \pm 3.09$ & 0.755 \\
\hline ALT & $35.26 \pm 13.25$ & $43.62 \pm 25.36$ & 0.392 & $35.94 \pm 21.32$ & $32.38 \pm 23.57$ & 0.363 \\
\hline AST & $43.27 \pm 21.76$ & $47.25 \pm 12.64$ & 0.778 & $35.77 \pm 14.53$ & $45.59 \pm 26.45$ & 0.277 \\
\hline ALP & $81.31 \pm 31.71$ & $136.73 \pm 93.25$ & 0.392 & $95.94 \pm 31.39$ & $132.88 \pm 57.56$ & 0.017 \\
\hline GGT & $74.88 \pm 38.26$ & $151.16 \pm 65.74$ & 0.249 & $65.67 \pm 45.46$ & $141.68 \pm 67.46$ & $<0.001$ \\
\hline PTA & $98.34 \pm 5.13$ & $99.53 \pm 3.35$ & 0.862 & $97.46 \pm 4.36$ & $98.56 \pm 3.21$ & 0.764 \\
\hline AFP & $5.23 \pm 2.48$ & $126.23 \pm 73.63$ & 0.171 & $6.49 \pm 4.44$ & $101.46 \pm 78.4$ & 0.021 \\
\hline PLT & $115.37 \pm 43.86$ & $132.26 \pm 48.34$ & 0.948 & $132.23 \pm 47.98$ & $131.28 \pm 28.42$ & 0.897 \\
\hline
\end{tabular}

TBIL, total bilirubin; PLT, platelets; PTA, prothrombin activity; ALB, albumin; ALT, alanine aminotransferase; AST, aspartate aminotransferase. The normal range of ALT and AST is 5-40 U/1, PLT is 100-300x10 $/ 1$, ALB is 35-55 g/l. a paired samples test.

Table III. Overview of reads from raw data to cleaned sequences.

\begin{tabular}{|c|c|c|c|c|c|c|c|c|c|}
\hline \multirow[b]{2}{*}{ Library } & \multirow[b]{2}{*}{ Type } & \multicolumn{4}{|c|}{ Cirrhosis } & \multicolumn{4}{|c|}{$\mathrm{HCC}$} \\
\hline & & Total & $\begin{array}{c}(\%) \text { of } \\
\text { total }\end{array}$ & Uniq & $\begin{array}{l}(\%) \text { of } \\
\text { uniq }\end{array}$ & Total & $\begin{array}{c}(\%) \text { of } \\
\text { total }\end{array}$ & Uniq & $\begin{array}{l}(\%) \text { of } \\
\text { uniq }\end{array}$ \\
\hline Raw reads & NA & $9,846,382$ & 100 & 958,733 & 100 & $9,342,644$ & 100 & 906,960 & 100 \\
\hline $\begin{array}{l}3 \text { ADT and } \\
\text { length filter }\end{array}$ & Sequence type & 863,846 & 8.77 & 332,485 & 34.68 & 848,736 & 9.08 & 302,543 & 33.36 \\
\hline Junk reads & Sequence type & 6,583 & 0.76 & 4,634 & 0.48 & 5,346 & 0.06 & 2,143 & 0.24 \\
\hline Rfam & RNA class & 447,513 & 4.54 & 59,567 & 6.21 & 512,456 & 5.49 & 55,354 & 6.10 \\
\hline mRNA & RNA class & 342,646 & 3.48 & 47,547 & 4.96 & 235,433 & 2.52 & 46,575 & 5.14 \\
\hline Repeats & RNA class & 76,869 & 0.78 & 11,086 & 1.16 & 98,574 & 1.06 & 8,756 & 0.97 \\
\hline rRNA & RNA class & 432,646 & 4.39 & 32,574 & 3.40 & 242,436 & 2.59 & 32,546 & 3.59 \\
\hline tRNA & RNA class & 123,247 & 1.25 & 18,644 & 1.94 & 115,364 & 1.23 & 15,364 & 1.69 \\
\hline snoRNA & RNA class & 32,536 & 0.33 & 6,537 & 0.68 & 20,123 & 0.22 & 4,365 & 0.48 \\
\hline snRNA & RNA class & 28,328 & 0.29 & 4,234 & 0.44 & 25,346 & 0.27 & 2,456 & 0.27 \\
\hline Other Rfam RNA & RNA class & 175,685 & 1.78 & 15,763 & 1.64 & 17,563 & 0.19 & 10,745 & 1.18 \\
\hline Clean reads & Sequence type & $7,248,031$ & 73.61 & 425,662 & 44.40 & $7,221,267$ & 77.29 & 426,113 & 46.98 \\
\hline
\end{tabular}

HCC, hepatocellular carcinoma; NA, not available.

the threshold. Using the comparative $\mathrm{Ct}$ method, the relative expression levels of miRNAs in serum were calculated using the formula for $2^{-\Delta \Delta \mathrm{Ct}}$, where $\Delta \Delta \mathrm{Ct}=[\mathrm{Ct}$ (target, test) - Ct (ref, test)] - [Ct (target, calibrator) - Ct (ref, calibrator)]. All primers used were obtained from Invitrogen (Carlsbad, CA, USA).

Statistical analysis. All Illumina sequencing data were $\log _{2}$ transformed. The differences between samples were calculated using Chi-square and Fisher's exact tests. Only the miRNAs with the fold-difference $>2.0$ and $\mathrm{P}<0.01$ were considered significant. Quantitative variables were expressed as mean \pm standard deviation (SD). Comparison of biochemical characteristics was conducted by paired-samples and the
Mann-Whitney test was used to compare the fold-differences of candidate miRNAs upon qRT-PCR in the validation data set, between cirrhosis and HCC status. All statistical analyses were performed using SPSS software, version 21.0 (SPSS, Inc., Chicago, IL, USA). All statistical tests were two-sided and the results were considered to indicate a statistically significant result when $\mathrm{P}<0.05$.

\section{Results}

Global analysis of miRNAs by deep sequencing. Illumina HiSeq 2000 sequencing of the small RNA library from the serum of the patients with cirrhosis and HCC produced 
A

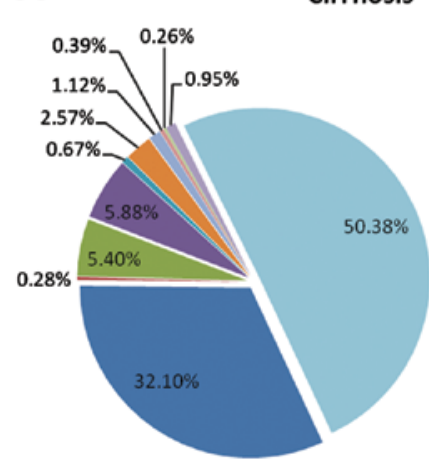

Cirrhosis

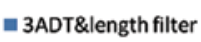

- Junk reads

n Rfam

mRNA

= Repeats

InRA

= IRNA

= SnORNA

In SnRNA

= other Rfam RNA

Elean reads
B

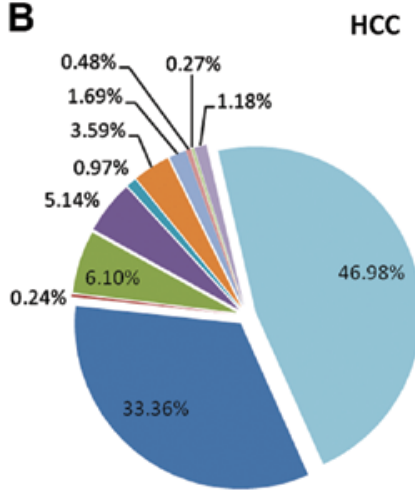

C

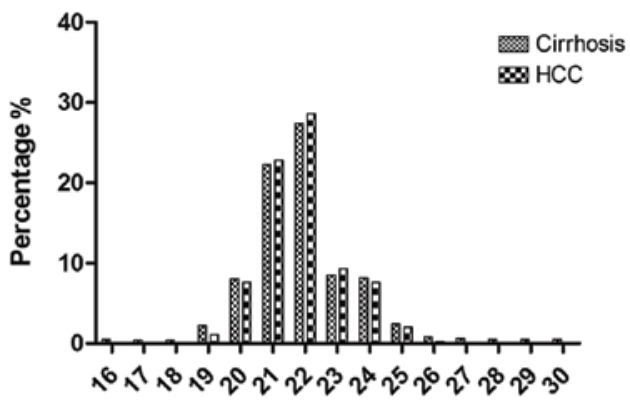

Length distribution of clean sequencing reads between 16 and $30 \mathrm{nt}$

Figure 1. Distribution of all reads from 16 to $30 \mathrm{nt}$ is presented in three groups.

9,846,382 and 9,342,644 raw reads, respectively. After extensive preprocessing and quality control, the raw reads were eventually removed, resulting in 425,662 and 426,113 clean reads, for cirrhosis and HCC status, respectively (Table III, Fig. 1A and B). The distribution of all reads between 16-30 nt is presented in Fig. 1C. In the present study, we found that the length of miRNAs was concentrated at 20 and $22 \mathrm{nt}$. A total of 1,653 unique reads were mapped to human miRNAs or pre-miRNAs from the iRbase database, and the pre-miRNAs could be further mapped to the human genome and expressed sequence tags (ESTs).

Identification of novel miRNAs. In total, 14 novel miRNA genes were identified in the two disease categories. The length of these candidate miRNAs ranged from 20 to $24 \mathrm{nt}$. The localization, sequence, structure and expression profile of these miRNAs are summarized in Table IV. However, several candidates among the predicted novel miRNAs were expressed at extremely low levels.

Analysis of differentially expressed miRNAs. When the cirrhosis and HCC status samples were compared, the differential expression levels of 127 miRNAs showed significant variability (Fig. 2). Among these, 22 miRNAs showed a $>2$-fold upregulation $(\mathrm{P}<0.01)$, and 2 miRNAs showed a $>2$-fold downregulation $(\mathrm{P}<0.01)$ in the cirrhosis and HCC patients (Table V).

Validation of the differentially expressed miRNAs. We used qRT-PCR to confirm the expression of 40 candidate miRNAs that were selected from the previous step in an independent cohort consisting of 22 serum samples. The threshold value for the miRNAs was determined as $\mathrm{Ct}<35$ and the detection rate $>75 \%$. We then calculated the $2^{-\Delta \Delta \mathrm{Ct}}$ of 40 candidate miRNAs in the 2 status types. Eight of the 40 miRNAs had significantly differential expression levels between the 2 statuses (Table VI). These miRNAs were hsa-miR-122-5p, hsa-miR-192-5p, hsa-miR-486-5p, hsamiR-193b-5p, hsa-miR-206, hsa-miR-141-3p, hsa-miR-199a-5p and hsa-miR-26a-5p.

\section{Discussion}

Since the discovery of circulating miRNAs, several studies have been conducted to investigate their potential as novel biomarkers in body fluid. Circulating miRNAs have already been shown to be relevant biomarkers for cancer detection, applicable in non-invasive diagnostic testing and have demonstrated several other successful applications (24-27). To date, three methods have mainly been used for the analysis of the expression profiles of circulating miRNAs in serum: qRT-PCR, microarray and next-generation sequencing technology (28). Although qRT-PCR has been widely employed for miRNA quantification, it is only capable of detecting a limited number of miRNAs at any one time. Microarray analysis, a high-throughput method, is capable of detecting only known fragments and is not suitable for detection of low-abundant miRNAs or for distinguishing between miRNAs with single nucleic acid polymorphisms. Compared to these techniques, next-generation sequencing technology appears to be more suitable for miRNA profiling. Thus, the Roche 454 Genome Sequencer, the Illumina Genome Analyzer and the ABI 


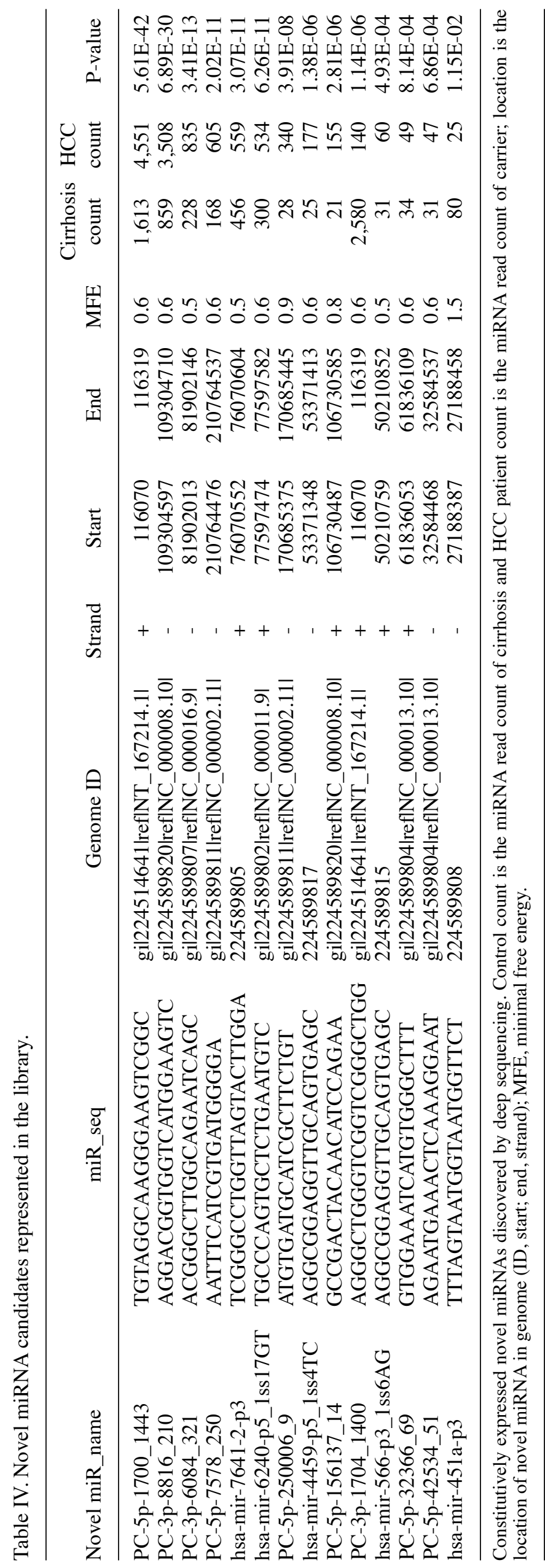

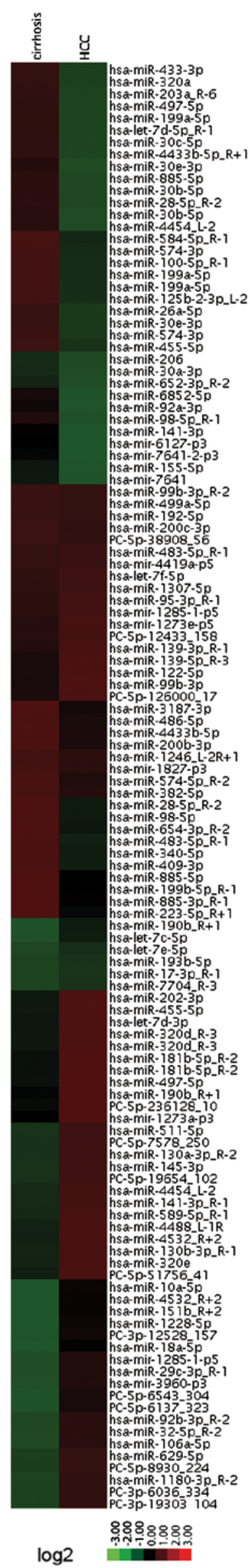

Figure 2. Heatmap of significantly differential expression levels of 127 miRNAs in the two disease caterories. 
Table V. Differential expression of miRNAs between HCC and cirrhosis.

\begin{tabular}{|c|c|c|c|c|c|}
\hline No. & miR_name & Fold-change & $\begin{array}{l}\text { Fold-change } \\
\quad(\log 2)\end{array}$ & Up/down & miR_seq \\
\hline 1 & hsa-miR-455-5p & 28.37 & 4.83 & $\mathrm{Up}$ & UAUGUGCCUUUGGACUACAUCG \\
\hline 2 & hsa-let-7e-5p & 26.25 & 4.71 & Up & UGAGGUAGGAGGUUGUAUAGUU \\
\hline 3 & hsa-miR-483-5p_R-1 & 22.60 & 4.50 & Up & AAGACGGGAGGAAAGAAGGGAG \\
\hline 4 & hsa-miR-190b_R+1 & 22.36 & 4.48 & Up & UGAUAUGUUUGAUAUUGGGUUU \\
\hline 5 & hsa-miR-30e-3p & 20.01 & 4.32 & $\mathrm{Up}$ & CUUUCAGUCGGAUGUUUACAGC \\
\hline 6 & hsa-miR-486-5p & 17.41 & 4.12 & Up & TCCTGTACTGAGCTGCCCCGAG \\
\hline 7 & hsa-miR-584-5p_R-1 & 11.08 & 3.47 & Up & UUAUGGUUUGCCUGGGACUGG \\
\hline 8 & hsa-miR-10a-5p & 10.45 & 3.38 & $\mathrm{Up}$ & UACCCUGUAGAUCCGAAUUUGUG \\
\hline 9 & hsa-miR-574-3p & 9.38 & 3.23 & Up & UGAGUGUGUGUGUGUGAGUGUGU \\
\hline 10 & hsa-miR-193b-5p & 9.13 & 3.19 & Up & CGGGGTTTTGAGGGCGAGATGA \\
\hline 11 & hsa-miR-4532_R+2 & 8.33 & 3.06 & $\mathrm{Up}$ & CCCCGGGGAGCCCGGCGCG \\
\hline 12 & hsa-miR-206 & 7.69 & 2.94 & $\mathrm{Up}$ & UGGAAUGUAAGGAAGUGUGUGG \\
\hline 13 & hsa-miR-28-5p_R-2 & 7.43 & 2.89 & Up & AAGGAGCUCACAGUCUUGAG \\
\hline 14 & hsa-miR-433-3p & 6.13 & 2.62 & Up & AUCAUGAUGGGCUCCUCGGUGU \\
\hline 15 & hsa-miR-3187-3p & 6.04 & 2.59 & Up & TTGGCCATGGGGCTGCGCGG \\
\hline 16 & hsa-miR-98-5p & 5.71 & 2.51 & Up & UGAGGUAGUAAGUUGUAUUGUU \\
\hline 17 & hsa-miR-4433b-5p & 5.29 & 2.40 & $\mathrm{Up}$ & AUGUCCCACCCCCACUCCUGU \\
\hline 18 & hsa-miR-497-5p & 4.94 & 2.30 & $\mathrm{Up}$ & CAGCAGCACACTGTGGTTTGT \\
\hline 19 & hsa-mir-1285-1-p5 & 4.60 & 2.20 & $\mathrm{Up}$ & GAUCUCACUUUGUUGCCCAGG \\
\hline 20 & hsa-miR-141-3p & 3.29 & 1.72 & $\mathrm{Up}$ & UAACACUGUCUGGUAAAGAUGG \\
\hline 21 & hsa-miR-100-5p_R-1 & 2.99 & 1.58 & Up & AACCCGUAGAUCCGAACUUGUG \\
\hline 22 & hsa-miR-99b-3p_R-2 & 2.36 & 1.24 & Up & CACCCGUAGAACCGACCUUG \\
\hline 32 & hsa-miR-199a-5p & 0.50 & -0.99 & Down & ACAGUAGUCUGCACAUUGGUUA \\
\hline 23 & hsa-miR-1228-5p & 0.49 & -1.03 & Down & GUGGGCGGGGGCAGGUGUGUG \\
\hline 24 & hsa-miR-202-3p & 0.48 & -1.05 & Down & AGAGGTATAGGGCATGGGAA \\
\hline 29 & hsa-miR-92a-3p & 0.46 & -1.13 & Down & TATTGCACTTGTCCCGGCCTGT \\
\hline 25 & hsa-miR-6852-5p & 0.45 & -1.14 & Down & CCCUGGGGUUCUGAGGACAUG \\
\hline 31 & hsa-miR-30b-5p & 0.45 & -1.14 & Down & UGUAAACAUCCUACACUCAGCU \\
\hline 33 & hsa-miR-511-5p & 0.44 & -1.18 & Down & GUGUCUUUUGCUCUGCAGUCA \\
\hline 27 & hsa-miR-320a & 0.37 & -1.44 & Down & AAAAGCTGGGTTGAGAGGGCGA \\
\hline 28 & hsa-mir-6127-p3 & 0.36 & -1.48 & Down & UGAGGGAGUGGGUGGGAGG \\
\hline 26 & hsa-miR-26a-5p & 0.36 & -1.48 & Down & UUCAAGUAAUCCAGGAUAGGCU \\
\hline 30 & hsa-miR-885-5p & 0.35 & -1.50 & Down & TCCATTACACTACCCTGCCTCT \\
\hline 34 & hsa-miR-30a-3p & 0.32 & -1.63 & Down & UGUAAACAUCCUCGACUGGAAG \\
\hline 35 & hsa-miR-4454_L-2 & 0.19 & -2.39 & Down & GGAUCCGAGUCACGGCACCA \\
\hline 36 & hsa-let-7c-5p & 0.08 & -3.61 & Down & UGAGGUAGUAGGUUGUAUGGUU \\
\hline 37 & hsa-miR-30c-5p & 0.06 & -4.17 & Down & UGUAAACAUCCUACACUCUCAGC \\
\hline 38 & hsa-let-7f-5p & 0.05 & -4.23 & Down & UGAGGUAGUAGAUUGUAUAGUU \\
\hline 39 & hsa-miR-122-5p & 0.03 & -5.00 & Down & UGGAGUGUGACAAUGGUGUUUG \\
\hline 40 & hsa-miR-192-5p & 0.03 & -5.00 & Down & CUGACCUAUGAAUUGACAGCC \\
\hline
\end{tabular}

HCC, hepatocellular carcinoma.

SOLiD System sequencing platforms have become widely available and used over the past few years.

Several studies have shown that many miRNAs are dysregulated in $\mathrm{HCC}(17,29,30)$ and have also considered the potential of circulating miRNA levels to affect HCC progression. The high stability of miRNAs in circulation suggests them for use as potentially ideal biomarkers, particularly for early-stage detection (4). Various studies have observed and explored the upregulation of circulating miR-21 (18,31), miR-222 (31) and miR-223 (32) in the serum/plasma of HBV- or HCV-associated HCC patients.

Downregulation of miRNAs is also a common finding in HBV-related HCC; in this case, these miRNAs act as tumor-suppressor genes. The pathological mechanisms of 
Table VI. Expression profiles of candidate miRNAs upon qRT-PCR in the validation set.

\begin{tabular}{|c|c|c|c|}
\hline \multirow[b]{2}{*}{ No. } & \multirow[b]{2}{*}{ miR_name } & \multicolumn{2}{|c|}{ HCC vs. cirrhosis } \\
\hline & & P-value & Fold-change \\
\hline 1 & hsa-miR-455-5p & 0.108 & 1.58 \\
\hline 2 & hsa-let-7e-5p & 0.063 & 4.50 \\
\hline 3 & hsa-miR-483-5p_R-1 & 0.108 & 3.19 \\
\hline 4 & hsa-miR-190b_R+1 & 0.246 & 3.47 \\
\hline 5 & hsa-miR-30e-3p & ND & ND \\
\hline 6 & hsa-miR-486-5p & 0.006 & 2.42 \\
\hline 7 & hsa-miR-584-5p_R-1 & 0.108 & 3.25 \\
\hline 8 & hsa-miR-10a-5p & 0.144 & 1.43 \\
\hline 9 & hsa-miR-574-3p & ND & ND \\
\hline 10 & hsa-miR-193b-5p & 0.008 & 2.64 \\
\hline 11 & hsa-miR-4532_R+2 & 0.023 & 1.23 \\
\hline 12 & hsa-miR-206 & 0.003 & 3.64 \\
\hline 13 & hsa-miR-28-5p_R-2 & 0.069 & 2.45 \\
\hline 14 & hsa-miR-433-3p & 0.108 & 1.64 \\
\hline 15 & hsa-miR-3187-3p & ND & ND \\
\hline 16 & hsa-miR-98-5p & 0.723 & 1.63 \\
\hline 17 & hsa-miR-4433b-5p & ND & ND \\
\hline 18 & hsa-miR-497-5p & $<0.001$ & 1.33 \\
\hline 19 & hsa-mir-1285-1-p5 & 0.012 & 1.64 \\
\hline 20 & hsa-miR-141-3p & 0.001 & 2.44 \\
\hline 21 & hsa-miR-100-5p_R-1 & 0.289 & 1.54 \\
\hline 22 & hsa-miR-99b-3p_R-2 & 0.125 & 2.14 \\
\hline 23 & hsa-miR-1228-5p & 0.268 & 2.54 \\
\hline 24 & hsa-miR-202-3p & ND & ND \\
\hline 25 & hsa-miR-6852-5p & ND & ND \\
\hline 26 & hsa-miR-26a-5p & 0.002 & 0.64 \\
\hline 27 & hsa-miR-320a & 0.056 & 0.53 \\
\hline 28 & hsa-mir-6127-p3 & 0.108 & 0.77 \\
\hline 29 & hsa-miR-92a-3p & 0.256 & 0.87 \\
\hline 30 & hsa-miR-885-5p & 0.442 & 0.65 \\
\hline 31 & hsa-miR-30b-5p & 0.256 & 0.45 \\
\hline 32 & hsa-miR-199a-5p & $<0.001$ & 0.53 \\
\hline 33 & hsa-miR-511-5p & 0.284 & 0.45 \\
\hline 34 & hsa-miR-30a-3p & 0.084 & 0.54 \\
\hline 35 & hsa-miR-4454_L-2 & ND & ND \\
\hline 36 & hsa-let-7c-5p & 0.073 & 0.65 \\
\hline 37 & hsa-miR-30c-5p & 0.077 & 0.76 \\
\hline 38 & hsa-let-7f-5p & 0.112 & 0.78 \\
\hline 39 & hsa-miR-122-5p & $<0.001$ & 0.12 \\
\hline 40 & hsa-miR-192-5p & $<0.001$ & 0.24 \\
\hline
\end{tabular}

ND, not determined; miRNA Ct value $>35$ and detection rate $<75 \%$. HCC, hepatocellular carcinoma. Bold text, significant differences.

tumor-suppressive miRNAs is involved in cell cycle arrest, increased apoptosis and eventual reductions in tumor angiogenesis and metastasis by inhibiting migration and invasion. Among these downregulated miRNAs, miR-122 and miR-199 appear to be particularly important in HCC (33-35). In the present study, we also found that the miRNA downregulated in cirrhosis status that evolved into HCC was miR-122, a liver-specific miRNA that is abundant in the liver and plays an important role in regulating hepatocyte development and differentiation $(36,37)$. The overexpression of miR-122 has been found to induce apoptosis and suppress proliferation in the human liver carcinoma cell lines HepG2 and Hep3B in vitro (38), and has been demonstrated in vivo directly by the generation of miR-122-knockout mice in liver cancer $(39,40)$.

The present study revealed that serum hsa-miR-486-5p, hsa-miR-193b-5p, hsa-miR-206, hsa-miR-141-3p, hsa-miR199a-5p, hsa-miR-122-5p, hsa-miR-192-5p and hsa-miR-26a-5p were potential circulating markers for HCC diagnosis, and 4 of these 8 miRNAs (miR-122, miR-199, miR-192 and miR-26a) in the present study have been previously reported to show differential expression $(19,41,42)$.

At the circulating blood level, $\mathrm{Xu}$ et al (18) reported that miR-21, miR-122 and miR-223 could be utilized in discriminating HCC patients from a healthy group. Qu et al (43) found that miR-16 has moderate diagnostic accuracy in HCC. Li et al (14) reported an extraordinarily high diagnostic accuracy for serum miRNA profiles in the diagnosis of HCC [area under the curve $(A U C)=0.97-1.00]$ with miR-10a, miR-125b, miR-223, miR-23a, miR-23b, miR-342-3p, miR-375, miR-423, miR-92a and miR-99a. However, the need for different markers for different group comparisons with different critical values in their study (HCC vs. healthy, HCC vs. HBV, healthy vs. HBV, healthy vs. HCV and HBV vs. HCV) raised concerns about the robustness of these markers.

In our previous study (20), we established a logistic model of miRNAs for the diagnosis of HCC in a larger sample size and independent validation set. However, in the previous study, the cirrhosis and HCC patients were different individuals. While the present study was limited by the sample size, its innovation was the successful investigation of two phases of disease status in the same individuals.

\section{Acknowledgements}

The authors thank LC Bio-Tech Inc. for the expert technical assistance. This study was supported by the Natural Science Foundation of Jiangsu Province, China (BK2011151) (http://www.jstd.gov.cn/), the Medical Project of the Health Department, Jiangsu Province (H201248) (http://www.jswst. gov.cn/), the Preventive Medicine Research Projects of Jiangsu Province (Y2012016) (http://www.jswst.gov.cn/), and the Social Development Project of Zhenjiang City (SH201346) (http://kjj.zhenjiang.gov.cn/).

\section{References}

1. Zemel R, Issachar A and Tur-Kaspa R: The role of oncogenic viruses in the pathogenesis of hepatocellular carcinoma. Clin Liver Dis 15: 261-279, vii-x, 2011.

2. Cui XW, Chang JM and Dietrich CF: Should hepatocellular carcinoma screening with ultrasound be recommended in hepatocellular carcinoma high-incidence areas? Hepatology 61: 1091-1092, 2015

3. Lo SS, Dawson LA, Kim EY, Mayr NA, Wang JZ, Huang Z and Cardenes HR: Stereotactic body radiation therapy for hepatocellular carcinoma. Discov Med 9: 404-410, 2010. 
4. Petrelli A, Perra A, Cora D, Sulas P, Menegon S, Manca C, Migliore C, Kowalik MA, Ledda-Columbano GM, Giordano S, et al: MicroRNA/gene profiling unveils early molecular changes and nuclear factor erythroid related factor 2 (NRF2) activation in a rat model recapitulating human hepatocellular carcinoma (HCC). Hepatology 59: 228-241, 2014.

5. Valadi H, Ekström K, Bossios A, Sjöstrand M, Lee JJ and Lötvall JO: Exosome-mediated transfer of mRNAs and microRNAs is a novel mechanism of genetic exchange between cells. Nat Cell Biol 9: 654-659, 2007.

6. Li Y and Kowdley KV: MicroRNAs in common human diseases. Genomics Proteomics Bioinformatics 10: 246-253, 2012.

7. Bala S, Petrasek J, Mundkur S, Catalano D, Levin I, Ward J, Alao H, Kodys K and Szabo G: Circulating microRNAs in exosomes indicate hepatocyte injury and inflammation in alcoholic, drug-induced, and inflammatory liver diseases. Hepatology 56: 1946-1957, 2012.

8. Waidmann O, Bihrer V, Pleli T, Farnik H, Berger A, Zeuzem S, Kronenberger B and Piiper A: Serum microRNA-122 levels in different groups of patients with chronic hepatitis B virus infection. J Viral Hepat 19: e58-e65, 2012.

9. Waidmann O, Köberle V, Brunner F, Zeuzem S, Piiper A and Kronenberger B: Serum microRNA-122 predicts survival in patients with liver cirrhosis. PLoS One 7: e45652, 2012.

10. Wang J,Li J, Shen J, Wang C, Yang L and Zhang X: MicroRNA-182 downregulates metastasis suppressor 1 and contributes to metastasis of hepatocellular carcinoma. BMC Cancer 12: 227, 2012.

11. Lamba V, Ghodke-Puranik Y, Guan W and Lamba JK: Identification of suitable reference genes for hepatic microRNA quantitation. BMC Res Notes 7: 129, 2014.

12. Kutay H, Bai S, Datta J, Motiwala T, Pogribny I, Frankel W, Jacob ST and Ghoshal K: Downregulation of miR-122 in the rodent and human hepatocellular carcinomas. J Cell Biochem 99: 671-678, 2006

13. Ladeiro Y, Couchy G, Balabaud C, Bioulac-Sage P, Pelletier L, Rebouissou S and Zucman-Rossi J: MicroRNA profiling in hepatocellular tumors is associated with clinical features and oncogene/tumor suppressor gene mutations. Hepatology 47 1955-1963, 2008.

14. Li LM, Hu ZB, Zhou ZX, Chen X, Liu FY, Zhang JF, Shen HB, Zhang CY and Zen K: Serum microRNA profiles serve as novel biomarkers for HBV infection and diagnosis of HBV-positive hepatocarcinoma. Cancer Res 70: 9798-9807, 2010.

15. Meng F, Henson R, Wehbe-Janek H, Ghoshal K, Jacob ST and Patel T: MicroRNA-21 regulates expression of the PTEN tumor suppressor gene in human hepatocellular cancer. Gastroenterology 133: 647-658, 2007.

16. Pineau P, Volinia S, McJunkin K, Marchio A, Battiston C, Terris B, Mazzaferro V, Lowe SW, Croce CM and Dejean A: miR-221 overexpression contributes to liver tumorigenesis. Proc Natl Acad Sci USA 107: 264-269, 2010.

17. Huang $X$ and Jia Z: Construction of HCC-targeting artificial miRNAs using natural miRNA precursors. Exp Ther Med 6: 209-215, 2013.

18. Xu J, Wu C, Che X, Wang L, Yu D, Zhang T, Huang L, Li H, Tan W, Wang C, et al: Circulating microRNAs, miR-21, miR-122, and miR-223, in patients with hepatocellular carcinoma or chronic hepatitis. Mol Carcinog 50: 136-142, 2011.

19. Zhou J, Yu L, Gao X, Hu J, Wang J, Dai Z, Wang JF, Zhang Z, Lu S, Huang X, et al: Plasma microRNA panel to diagnose hepatitis B virus-related hepatocellular carcinoma. J Clin Oncol 29: 4781-4788, 2011

20. Tan Y, Ge G, Pan T, Wen D, Chen L, Yu X, Zhou X and Gan J: A serum microRNA panel as potential biomarkers for hepatocellular carcinoma related with hepatitis B virus. PLoS One 9: e107986, 2014

21. Tan Y, Ge G, Pan T, Wen D and Gan J: A pilot study of serum microRNAs panel as potential biomarkers for diagnosis of nonalcoholic fatty liver disease. PLoS One 9: e105192, 2014.

22. Peltier HJ and Latham GJ: Normalization of microRNA expression levels in quantitative RT-PCR assays: Identification of suitable reference RNA targets in normal and cancerous human solid tissues. RNA 14: 844-852, 2008.

23. Zhang H, Li QY, Guo ZZ, Guan Y, Du J, Lu YY, Hu YY, Liu P, Huang $S$ and Su SB: Serum levels of microRNAs can specifically predict liver injury of chronic hepatitis B. World J Gastroenterol 18: 5188-5196, 2012.
24. Li G, Cai G, Li D and Yin W: MicroRNAs and liver disease: Viral hepatitis, liver fibrosis and hepatocellular carcinoma. Postgrad Med J 90: 106-112, 2014.

25. Li ZJ, Ou-Yang PH and Han XP: Profibrotic effect of miR-33a with Akt activation in hepatic stellate cells. Cell Signal 26: 141-148, 2014.

26. Marin JJ, Bujanda L and Banales JM: MicroRNAs and cholestatic liver diseases. Curr Opin Gastroenterol 30: 303-309, 2014.

27. Papaconstantinou I, Karakatsanis A, Gazouli M, Polymeneas G and Voros D: The role of microRNAs in liver cancer. Eur J Gastroenterol Hepatol 24: 223-228, 2012.

28. Mei Q, Li X, Meng Y, Wu Z, Guo M, Zhao Y, Fu X and Han W: A facile and specific assay for quantifying microRNA by an optimized RT-qPCR approach. PLoS One 7: e46890, 2012.

29. Salvi A, Abeni E, Portolani N, Barlati S and De Petro G: Human hepatocellular carcinoma cell-specific miRNAs reveal the differential expression of miR-24 and miR-27a in cirrhotic/ non-cirrhotic HCC. Int J Oncol 42: 391-402, 2013.

30. Xu RH, Zheng LY, He DL, et al: Profiling of differentially expressed microRNAs (miRNAs) during differentiation of rat hepatic oval cells (HOCs) into hepatocellular carcinoma (HCC) cells. Clin Transl Oncol 17: 230-237, 2015.

31. Li J, Wang Y, Yu W, Chen J and Luo J: Expression of serum miR-221 in human hepatocellular carcinoma and its prognostic significance. Biochem Biophys Res Commun 406: 70-73, 2011.

32. Tomimaru Y, Eguchi H, Nagano H, Wada H, Kobayashi S, Marubashi S, Tanemura M, Tomokuni A, Takemasa I, Umeshita K, et al: Circulating microRNA-21 as a novel biomarker for hepatocellular carcinoma. J Hepatol 56: 167-175, 2012.

33. Murakami Y, Yasuda T, Saigo K, Urashima T, Toyoda H, Okanoue $\mathrm{T}$ and Shimotohno K: Comprehensive analysis of microRNA expression patterns in hepatocellular carcinoma and non-tumorous tissues. Oncogene 25: 2537-2545, 2006.

34. Jiang J, Gusev Y, Aderca I, Mettler TA, Nagorney DM, Brackett DJ, Roberts LR and Schmittgen TD: Association of microRNA expression in hepatocellular carcinomas with hepatitis infection, cirrhosis, and patient survival. Clin Cancer Res 14: 419-427, 2008.

35. Hou J, Lin L, Zhou W, Wang Z, Ding G, Dong Q, Qin L, Wu X, Zheng Y, Yang Y, et al: Identification of miRNomes in human liver and hepatocellular carcinoma reveals miR-199a/b-3p as therapeutic target for hepatocellular carcinoma. Cancer Cell 19: 232-243, 2011.

36. Morita K, Taketomi A, Shirabe K, Umeda K, Kayashima H, Ninomiya M, Uchiyama H, Soejima Y and Maehara Y: Clinical significance and potential of hepatic microRNA-122 expression in hepatitis C. Liver Int 31: 474-484, 2011.

37. Chang J, Nicolas E, Marks D, Sander C, Lerro A, Buendia MA, Xu C, Mason WS, Moloshok T, Bort R, et al: miR-122, a mammalian liver-specific microRNA, is processed from her mRNA and may downregulate the high affinity cationic amino acid transporter CAT-1. RNA Biol 1: 106-113, 2004.

38. Datta J, Kutay H, Nasser MW, Nuovo GJ, Wang B, Majumder S, Liu CG, Volinia S, Croce CM, Schmittgen TD, et al: Methylation mediated silencing of microRNA-1 gene and its role in hepatocellular carcinogenesis. Cancer Res 68: 5049-5058, 2008.

39. Hsu SH, Wang B, Kota J, Yu J, Costinean S, Kutay H, Yu L, Bai S, La Perle K, Chivukula RR, et al: Essential metabolic, anti-inflammatory, and anti-tumorigenic functions of miR-122 in liver. J Clin Invest 122: 2871-2883, 2012.

40. Tsai WC, Hsu SD, Hsu CS, Lai TC, Chen SJ, Shen R, Huang Y, Chen HC, Lee CH, Tsai TF, et al: MicroRNA-122 plays a critical role in liver homeostasis and hepatocarcinogenesis. J Clin Invest 122: 2884-2897, 2012.

41. Kota J, Chivukula RR, O'Donnell KA, Wentzel EA, Montgomery CL, Hwang HW, Chang TC, Vivekanandan P, Torbenson M, Clark KR, et al: Therapeutic microRNA delivery suppresses tumorigenesis in a murine liver cancer model. Cell 137: 1005-1017, 2009.

42. Ji J, Shi J, Budhu A, Yu Z, Forgues M, Roessler S, Ambs S, Chen Y, Meltzer PS, Croce CM, et al: MicroRNA expression, survival, and response to interferon in liver cancer. N Engl J Med 361: 1437-1447, 2009.

43. Qu KZ, Zhang K, Li H, Afdhal NH and Albitar M: Circulating microRNAs as biomarkers for hepatocellular carcinoma. J Clin Gastroenterol 45: 355-360, 2011. 